\title{
Use of regadenoson in end-stage renal disease
}

\author{
Ami E. Iskandrian, MD, MACC, ${ }^{\mathrm{a}, \mathrm{b}}$ Fadi G. Hage, MD, FACC, ${ }^{\mathrm{a}, \mathrm{b}}$ and \\ Jaekyeong Heo, MD, FACC ${ }^{\mathrm{a}, \mathrm{b}}$
}

\section{See related article, pp. 205-213}

Regadenoson has rapidly become the pharmacological stress agent of choice in the United States since its approval by the Food and Drug Administration in April 2008. ${ }^{1-5}$ The effect of regadenoson on myocardial blood flow is rapid necessitating the injection of radionuclide tracer 30 seconds after its injection as a bolus. The terminal part of the triphasic half-life is not associated with significant drug effect of any sort, which is important as prolonged monitoring of the patient is unnecessary. Almost $57 \%$ of the drug is excreted unchanged in the urine, which begs the question of safety in patients with impaired renal function. 6,7

It is against this background that the study of Doukky et $\mathrm{al}^{8}$ in this issue of the Journal becomes important. The authors assembled a group of patients with end-stage renal disease $(\mathrm{ESRD}, \mathrm{n}=146$ ) stages 5 (on dialysis or with GFR $<15 \mathrm{~mL} /$ minute $/ 1.73 \mathrm{~m}^{2}$ and not yet on dialysis) and compared their responses (see below) to a control group with GFR $>30(\mathrm{n}=97)$. The 2 groups were selected from identically designed randomized studies that addressed the usefulness of aminophylline in reducing the side effects of regadenoson (one trial was in ESRD patients while the 2nd was open to all patients). ${ }^{9,10}$ The primary end-point of both trials was any adverse event over a 24-hour period after the stress test. The secondary end points were multiple and included hemodynamic responses, ECG changes, aminophylline use, gastro-intestinal symptoms, broncho-spasm, comfort level, and willingness to undergo the test again.

From the Division of Cardiovascular Diseases, ${ }^{\text {a }}$ University of Alabama at Birmingham, Birmingham, AL; and Section of Cardiology, Birmingham Veteran's Administration Medical Center, Birmingham, AL.

Reprint requests: Ami E. Iskandrian, MD, MACC, Division of Cardiovascular Diseases, University of Alabama at Birmingham, 318 LHRH, 1900 University BLVS, Birmingham, AL 35294; aiskand@uab.edu.

J Nucl Cardiol 2013;20:182-4.

$1071-3581 / \$ 34.00$

Copyright $@ 2012$ American Society of Nuclear Cardiology.

doi:10.1007/s12350-012-9658-y
The patients with ESRD are an important group of patients because of the high total and cardiovascular mortality rates especially sudden death. In prior studies, left ventricular (LV) ejection fraction (EF), ischemic burden, scar burden, autonomic neuropathy measured indirectly with the heart rate response to adenosine or regadenoson and LV dyssynchrony (measured with phase analysis of gated SPECT myocardial perfusion imaging) were found to be predictors of outcome in this population. $^{11-16}$

The main conclusion of the study presented here is that regadenoson is safe in ESRD with an overall sideeffect profile comparable to that seen in the control group. Specifically, there were no serious side effects such as death, cardiac arrest, hospitalization, or bronchospasm seen in either group. While a single participant in the control group experienced self-limited hypotension, this was not seen in any subject with ESRD. None of the subjects in either group had ventricular tachyarrhythmia, third-degree or second-degree type-2 atrioventricular block. Two participants with ESRD had Mobitz type-1 second-degree atrio-ventricular block (Wenckebach block) and one participant in each group had first-degree block (all these events were rare and not significantly different between groups). Premature ventricular contractions were more common in ESRD than in control subjects ( $8 \%$ vs $1 \%, P=.02$ ) but this finding is of uncertain clinical significance and may have been present before the test as well.

There were more gastro-intestinal symptoms (diarrhea and abdominal discomfort) but less dizziness in the ESRD group than in the control group. ${ }^{8}$ However, more patients in the ESRD group than in the control group felt comfortable with the test and were willing to undergo repeated testing than in the control group. The differences in heart rate and blood pressure responses were minor and of no clinical relevance.

This study therefore supports prior observational studies that showed the safety of regadenoson in ESRD. ${ }^{17,18}$ The precise reason for the higher incidence of diarrhea in ESRD is not clear and the increase in halflife of regadenoson does not appear to fully explain this as these patients had frequent bowel movements while still in the laboratory and not in the subsequent 24 hours.

We obviously do not know the prior history of the bowel habits in these patients before the stress test and 
there was no control over their dietary intake after the test. There were also many differences between the ESRD group and the control group in age, ethnicity, gender, diabetes, and the indications for testing. It should also be pointed out that the patients were given two interviews, one after the stress test and the second 24 hours later and hence many trivial complaints may have been registered. This may explain the higher incidence of side effects in general and the higher rate of use of aminophylline compared to other trials. ${ }^{19}$

The drug information package lists diarrhea in $<1 \%$ and dizziness in $8 \%$ of unselected patients receiving regadenoson, clearly much less than the corresponding numbers in the control group in this study. One possible reason for these differences is that these patients were bombarded by questions throughout the procedure and their awareness that they were in a research study with a chance of 1 in 2 of receiving an active drug rather than a placebo.

The strengths of the study by Doukky et al are the prospective nature and the details of safety information collected over a 24-hour period. ${ }^{8}$ The weaknesses include the fact it is not a randomized study with major inequalities in baseline characteristics of the patients and the control group. In the pursuit of completeness many meaningless complaints of mild nature were elicited (not volunteered by the patients) but listed nevertheless as side effects. These minor side effects have no real clinical relevance as seen by the dissociation between them and the comfort score; the ESRD patients had more diarrhea and yet were more comfortable than the control group and more willing to undergo repeated testing if needed! We do not know whether the ESRD patients had more diarrhea, even before the stress test possibly because of diabetic neuropathy.

In summary, this study provides further assurance that regadenoson could be safely used in patients with ESRD.

\section{Conflict of interest}

Dr Iskandrian is on the steering committee of Astellas Pharma. Drs. Hage and Iskandrian report investigatorinitiated grant support from Astellas Pharma.

\section{References}

1. Iskandrian AE, Bateman TM, Belardinelli L, Blackburn B, Cerqueira MD, Hendel RC, et al. Adenosine versus regadenoson comparative evaluation in myocardial perfusion imaging: Results of the ADVANCE phase 3 multicenter international trials. J Nucl Cardiol 2007; 14:645-58.

2. Lieu HD, Shryock JC, von Mering GO, Gordi T, Blackburn B, Olmsted AW, et al. Regadenoson, a selective A2A adenosine receptor agonist, causes dose-dependent increases in coronary blood flow velocity in humans. J Nucl Cardiol 2007;14:514-20.

3. Cerqueira MD, Nguyen P, Staehr P, Underwood SR Sr, Iskandrian $\mathrm{AE}$, on behalf of the ADVANCE-MPI Trial Investigators. Effects of age, gender, obesity, and diabetes on the efficacy and safety of the selective A2A agonist regadenoson versus adenosine in myocardial perfusion imaging: Integrated ADVANCE-MPI trial results. J Am Coll Cardiol Imaging 2008;1:307-16.

4. Zoghbi GJ, Iskandrian AE. Selective adenosine agonists and myocardial perfusion imaging. J Nucl Cardiol 2012;19:126-41.

5. Iskandrian AE, Garcia EV, editors. Nuclear cardiac imaging: Principles and applications. 4th ed. Oxford: Oxford University Press; 2008.

6. Gordi T, Frohna P, Sun HL, Wolff A, Belardinelli L, Lieu H. A population pharmacokinetic/pharmacodynamic analysis of regadenoson, an adenosine A2a-receptor agonist, in healthy male volunteers. Clin Pharmacokinet 2006;45:1201-12.

7. Gordi T, Blackburn B, Lieu H. Regadenoson pharmacokinetics and tolerability in subjects with impaired renal function. J Clin Pharmacol 2007;47:825-33.

8. Doukky R, Rangel MO, Wassouf M, Dick R, Alqaid A, Demori RM. The safety and tolerability of regadenoson in patients with end-stage renal disease: The first prospective evaluation. J Nucl Cardiol. doi:10.1007/s12350-012-9654-2.

9. Rangel MO, Dick R, Wassouf M, Alqaid A, Morales Demori R, et al. Attenuation of the side effect profile of regadenoson: A randomized double-blind placebo-controlled study with aminophylline in patients with severe chronic kidney disease undergoing myocardial perfusion imaging-The ASSUAGE-CKD Trial. J Nucl Cardiol 2012;19:448-57.

10. Doukky R, Demori RM, Jain S, Kiriakos R, Mwansa V, Calvin JE. Attenuation of the side effect profile of regadenoson: A randomized double-blinded placebo-controlled study with aminophylline in patients undergoing myocardial perfusion imaging. "The ASSUAGE trial". J Nucl Cardiol 2012;19:448-57.

11. Hage FG, Smalheiser S, Zoghbi GJ, Perry GJ, Deierhoi M, Warnock D, et al. Predictors of survival in patients with end-stage renal disease evaluated for kidney transplantation. Am J Cardiol 2007;100:1020-5.

12. Venkataraman R, Hage FG, Dorfman T, Heo J, Aqel RA, de Mattos AM, Iskandrian AE. Role of myocardial perfusion imaging in patients with end-stage renal disease undergoing coronary angiography. Am J Cardiol 2008;102:1451-6.

13. Patel AD, Abo-Auda WS, Davis JM, Zoghbi GJ, Deierhoi MH, Heo J, et al. Prognostic value of myocardial perfusion imaging in predicting outcome after renal transplantation. Am J Cardiol 2003;92:146-51.

14. Hage FG, Dean P, Bhatia V, Iqbal F, Heo J, Iskandrian AE. The prognostic value of the heart rate response to adenosine in relation to diabetes mellitus and chronic kidney disease. Am Heart $\mathbf{J}$ 2011;162:356-62.

15. Al-Mallah MH, Hachamovitch R, Dorbala S, Di Carli MF. Incremental prognostic value of myocardial perfusion imaging in patients referred to stress single-photon emission computed tomography with renal dysfunction. Circ Cardiovasc Imaging 2009;2:429-36.

16. Aggarwal H, Mehta S, Mannon R, Heo J, Iskandrian AE, Hage FG. Heart rate response to adenosine is an independent predictor of long-term mortality in end-stage renal disease. Circulation 2012;126:Number 18036.

17. Palani G, Husain Z, Salinas RC, Karthikeyan V, Karthikeyan AS, Ananthasubramaniam K. Safety of regadenoson as a pharmacologic stress agent for myocardial perfusion imaging in chronic 
kidney disease patients not on hemodialysis. J Nucl Cardiol 2011;18:605-11.

18. Aljaroudi W, Hermann D, Hage F, Heo J, Iskandrian AE. Safety of regadenoson in patients with end-stage renal disease. Am J Cardiol 2010;105:133-5.
19. Ananthasubramaniam K, Weiss R, McNutt B, Klauke B, Feaheny $\mathrm{K}$, Bukofzer S. A randomized, double-blind, placebo-controlled study of the safety and tolerance of regadenoson in subjects with stage 3 or 4 chronic kidney disease. J Nucl Cardiol 2012;19:31929. 